\title{
Study on the Measures of Preventing Harm in Physical Education Training in Colleges
}

\author{
Jie Wang
}

University of Electronic Science and Technology of China, Chengdu, Sichuan, 610054

Keywords: Analysis of College Physical Education, Teaching, Injury Prevention and Sports Training

\begin{abstract}
Sports training plays an important role in college PE teaching in China. It is an important part of PE teaching in modern Colleges. It is also of great significance to further improve the modern education system in China. Carrying out sports training teaching practice in Colleges is conducive to further enhancing the level of physical education and physical quality, as well as the overall quality of their improvement, but also to providing effective protection for college students' physical health. This paper analyzes the injury prevention measures in college sports training, discusses some common forms of sports injuries, and provides some references for further promoting college sports training.
\end{abstract}

\section{Introduction}

In Colleges at this stage, college students are often poor physical fitness, lack of active training initiative, which requires us to pay more attention to the development of college sports training to further solve these problems. Sports training is an important part of college teaching system and plays a key role in promoting the development of college physical education. Sports injury training is also common in sports training, requiring us to take timely measures to solve the problem, to avoid affecting the process of sports training, but also not conducive to the future of sports teaching.

\section{The definition and types of student sports injuries}

Student injuries are conditional restrictions, mainly in the main body, space, time on three aspects. That is, the main body is a school-going student, the space is within the school-related infrastructure, and the time is in education and teaching activities implemented by the school or out of school activities organized by the school. Refers to students in school teaching activities or activities organized by the school, as well as school-related teaching facilities in the casualties occurred in the accident.

The types of student injuries mainly include the following: 1. Accidents in school classrooms or school dorms due to unsafe equipment. 2. Accidents on school diets. 3, school teaching or extracurricular activities in the event of accidents; 4, schools and teachers due to mismanagement caused by accidents; 5 , school activities in the organization of accidents; 6 , students take care of their body ill-accident; 7 , The school did not timely rescue accident occurred in the accident; 8 , the teacher's own behavior there is a mistake on the accident; 9, the teacher not as an accident; 10, the school failed to fulfill the obligation to inform the obligation.

\section{Injuries in college sports training accident}

Injury accidents often appear in college sports training, which requires us to take a scientific and effective way to deal with, in order to better promote the development of college sports training, but also for teachers to find a new way for teaching sports to lay a foundation.

In college physical education training, each participant is a relatively independent individual for participating students. There are unique characteristics in their own characteristics, and there are obvious differences among themselves. This has led to its obvious psychological and athletic 
performance in participating in college sports training in many aspects showed obvious needless, which also makes college physical injury training there is a personality characteristics, in each person's performance is different. The uniqueness of the students themselves is also an important reason for their injuries in sports training. It requires us to further recognize the characteristics of the students in the practice of college physical education in order to further carry out the teaching of physical education and optimize the teaching methods.

In college sports training, there are a variety of forms of sports training, which leads to different forms of injury in different forms of training students. For example, college sports there are antagonistic basketball games, badminton competitions, there are also the need for explosive power long-distance race, etc., different forms of exercise led to the form of injury to some extent, there are differences.

Sports injuries have obvious unpredictable characteristics. With the implementation of college physical education training courses, students must take effective safety precautions to avoid sports training injury and harm to health. However, from the perspective of the form of self-protection of college students in our country at present, the proportion of students taking corresponding protective measures in intense sports is still in a relatively small proportion, and the safety consciousness of college students is poor. Teachers in the process of teaching, to strengthen students' awareness of safety precautions to guide the formation of self-protection awareness, reduce injuries in sports training situation.

\section{The analysis of the main problems in the current college sports training}

In the current university sports training, the students' self-protection awareness is poor, which leads them to not take any self-protection measures in training, and lack the ability to deal with the injuries in a timely manner and to solve them. With the continuous enrichment of sports training courses, there are also different kinds of sports in physical education curriculum, which greatly stimulates students' interest in participation and arouse their enthusiasm for learning. This also includes a somewhat complex and difficult course of training content, because some students do not form a good safety awareness of difficult training, leading to its training was severely harmed. This needs to further enhance students' self-protection awareness and take effective measures to deal with them.

In the teaching of college physical education, there is a general low quality of physical education teachers. The quality of physical education teachers has a crucial impact on the teaching of physical education and physical training. Many teachers in the teaching process only focus on the students' sports knowledge and skills teaching and training, neglect to enhance students' awareness of safety education, did not realize the importance of strengthening students' sense of self-protection, which led to the students Physical health has not been effectively protected. Moreover, the low quality of physical education teachers is also reflected in corporal punishment of students, and in the process of corporal punishment did not provide students with safety measures to make their safety at risk. Low-quality teachers are not conducive to the education of physical education training activities. Therefore, to further enhance the personal qualities of teachers, better to promote the development of college physical education.

In the current university sports training, the school neglects to propose and implement the strategy of preventing and injuring sports, and has not established a corresponding sports injury management system. Making it lack of institutional security in the process of physical education. For example, some schools do not carry out regular inspections and maintenance work on sports facilities. Many sports facilities have some safety hazards in terms of safety and product performance so that students are more likely to have injuries during physical training. Provide security during exercise. In addition, the school does not regularly carry out PE teacher safety training. Training can prompt physical education teachers to know what to do when they encounter sports injuries and how to deal with students falling down during exercise. As the school did not carry out the necessary knowledge training courses, which is more unfavorable to enhance student safety awareness, so that the sports injury prevention system is difficult to further improve and 
develop.

In the process of PE teaching in our country, there are serious problems such as the small size of sports field and the old sports equipment, which hinders the development of PE teaching work and also more easily leads to the occurrence of sports training accidents. First of all, due to the small size of the stadium, students are prone to collisions during exercise, resulting in injuries to their bodies. Second, there are also some problems in the sports equipment, the equipment is too old so that students have a lot of security risks in the course of the use, easily lead to accidents. For example, double pole, horizontal bar and other mechanical facilities due to long-term use and not timely replacement, particularly prone to sports safety problems, resulting in training injuries.

\section{The analysis of physical education in college sports training}

We should further enhance the students' awareness of safety in Colleges in our country, enhance their awareness of self-protection and avoid harms in training. Training students together can easily lead to injuries. As a school should take active and effective measures to strengthen students' awareness of safety and vigorously promote sports safety awareness, including teachers in teaching should also be actively taught to students the concept of safety awareness, so as to college students in sports training Provide security, reduce the occurrence of sports injuries.

For the current college physical education, teachers generally lower quality, the school should further improve the level of quality and professional ethics. Teachers should actively change teaching concepts, attaches great importance to the instillation of students' awareness of sports safety, and enhances students' sense of self-protection. They should not just focus on the teaching of students' theoretical knowledge. Students lacking the awareness of safety protection should be patiently trained to help them raise their awareness of protection and promptly respond to the occurrence of accidents and promptly put forward effective measures to solve them. We must also take precautionary measures to protect the safety of students and provide them with safety and security. Schools should also vigorously publicize safety education related knowledge, carry out regular teacher training activities on physical training, enhance physical education teachers' awareness of injuries and deal with sports accidents. In the process of sports training, teachers should actively provide students with relevant guidance so as to help students to further enhance their sports ability in training so as to enhance their ability to deal with unexpected injuries. Further enhance the safety of sports training and promote the development of anti-injury work in sports training in Colleges in our country.

Colleges in carrying out sports training, we must further improve the anti-injury mechanism to strengthen anti-injury measures in the construction work. To provide students with safety and security. Schools should also further strengthen the maintenance of sports infrastructure, the old sports equipment to be updated and returned in a timely manner, new equipment to be carried out on a regular basis to prevent its use in any problems, harm students. For example, relevant departments within the school can maintain the sports training facilities to ensure the safety of sports facilities. Schools can establish prevention and protection system and establish related management mechanism to promote the safe development of physical education in Colleges.

In the college physical education training work should be done before the relevant preparatory activities, it can further prevent the occurrence of accidental injuries in sports training for students in training to provide a degree of security, to help students adjust their physical condition, to achieve Better exercise status. For teachers, preparation should be based on actual training. For example, for more aggressive sports, such as basketball games, do not need to do high-intensity preparation activities, as long as to help students adjust the state of movement can be timely. For some soothing exercise, such as jogging, etc., teachers should further improve the intensity of preparation activities, but also to appropriately increase the time to prepare for the event. At the same time, teachers in teaching to tell students in advance of possible movement in the situation, tell the students corresponding solutions to students in order to better control the situation and solve their own problems. Through teaching practice work can help students do a good job before the training exercise preparation, to adapt to the rhythm of training, and actively adjust the state of 
exercise, to avoid accidental injuries in sports accidents.

In the practice of efficient sports teaching process, teachers must control the training interval time, to avoid the intensity of the training students cause physical injury. For example, after a sport is over, the teacher can lead the entire team to take a slow walk around the playground and prevent some students from sitting directly on the ground after exercising. Teachers may allow the students to drink water and rest after walking for some time. Meanwhile, intermittent time and form must reflect the relevant requirements of physical education teaching content. For example, sport focuses on upper extremity exercises, and during intermittent periods the teacher can shift training to lower experience exercises and vice versa. Through the control of intermittent exercise time, the scientific transfer of sports links, to further optimize the student's body blood supply environment, can actively prevent sports training injury.

\section{Conclusions}

With the development of college physical education, we should also pay more attention to the injuries that may occur in sports and actively propose measures to prevent injury in a reasonable and effective solution. This paper simply analyzes the relevant measures to prevent injuries in the physical education training in Baoding University. In the training of students, the teachers must further improve their own quality and change their teaching concepts so as to enhance their own awareness of safety protection. They fully realize that physical education is different from other teaching methods the characteristics of using the correct teaching methods for teaching. There are still many problems in sports training, including the lack of awareness of student safety and teachers' qualities to be improved. This requires us to actively solve and promote the further development of college physical education.

\section{References}

[1] Yang Lihua. Current Situation and Countermeasures of After-class Physical Training in Colleges [J]. Industry and Technology Forum, 2014, 13 (15): 222-223.

[2] Xie Weiping, strict May Fourth. Research on Injury Prevention in College Physical Education [J]. Exam Weekly (Physical Education and Research), 2014 (75).

[3] Wang Zhenjing. Study on the Causes of Physical Education Master in Suzhou Normal University [D]. Suzhou University, 2014.

[4] Huang Zhaowei. Study on Injuries Prevention in Physical Education Training of Colleges [J]. Contemporary Sport Science and Technology, 2015, 5 (08): 36-37. 